\title{
Predicting Who Will Develop Dementia in a Cohort of Canadian Seniors
}

\author{
David B. Hogan and Erika M. Ebly
}

\begin{abstract}
Objectives: We examined whether easily attainable variables were useful in predicting who became demented over a five year period and determined the rates of incident dementia for different categories of mild cognitive impairment. Methods: This was a cohort study of subjects recruited nationally in a population-based survey of Canadians 65 years and older (the Canadian Study of Health and Aging). After standardized clinical assessments, a subset of subjects $(\mathrm{n}=1782)$ was categorized as not demented at time one. Identical study methods allowed a reassessment of the cognitive status of surviving subjects ( $\mathrm{n}=892$ ) five years later. Results: Three baseline variables (Modified Mini Mental State (3MS) score, subject's age, and an informant's report of the presence of memory problems) were statistically significant predictors of the development of a dementia. An equation incorporating these three variables had a sensitivity of $79 \%$ and a specificity of $56 \%$ for predicting dementia among survivors at time two. An equation substituting the MMSE for the 3MS showed similar results. The various categories of mild cognitive impairment examined showed significantly different likelihoods for the subsequent development of a dementia. Some categories with a higher dementia risk were characterized by inclusion criteria requiring neuropsychological test scores that were greater than one standard deviation (SD) below the mean of age based normative data. Conclusion: In the absence of extensive laboratory, radiologic or neuropsychological tests, simple variables that can be easily determined in the course of a single clinical encounter were useful in predicting subjects with a higher risk of developing dementia. Attempts to use neuropsychological results to predict the development of dementia should look for significant impairments on age-standardized tests.
\end{abstract}

RÉSUMÉ: Prédiction de la démence dans une cohorte de Canadiens âgés. Objectifs: Nous avons évalué si des variables facilement accessibles peuvent être utiles pour prédire qui deviendra dément dans les cinq prochaines années et nous avons déterminé l'incidence de la démence pour différentes catégories de déficits cognitifs légers. Méthodes: Il s'agit d'une étude de cohorte portant sur des sujets âgés de 65 ans et plus, recrutés à travers le Canada dans le cadre d'une étude de population (l'étude Canadienne sur la santé et le vieillissement). Suite à une évaluation clinique standardisée, un sous-groupe de sujets $(\mathrm{n}=1782)$ ont été classifiés comme déments au temps 1 . Des méthodes d'étude identiques ont permis une réévaluation du statut cognitif des sujets survivants $(\mathrm{n}=892)$ cinq ans plus tard. Résultats: Trois variables de l'évaluation initiale (le score du mini mental modifié, l'âge du sujet et les troubles de mémoire rapportés par un informateur) étaient des prédicteurs significatifs du développement d'une démence. Une équation incorporant ces trois variables avait une sensibilité de $79 \%$ et une spécificité de $56 \%$ pour prédire la démence parmi les survivants au temps 2 . Les différentes catégories de déficits cognitifs légers examinés ont montré des probabilités significativement différentes pour le développement subséquent d'une démence. Certains sous-groupes comportaient un risque plus élevé de démence notamment ceux dont les scores des tests neuropsychologiques étaient de plus d'une déviation standard sous la moyenne normative pour l'âge. Conclusion: En l'absence d'épreuves biologiques, radiologiques ou neuropsychologiques poussées, des variables simples qui peuvent être déterminées au cours d'une seule entrevue clinique ont été utiles pour prédire quels sujets avaient un risque plus élevé de développer une démence. Si des tests neuropsychologiques sont utilisés pour prédire le développement d'une démence on devrait rechercher des déficits significatifs au moyen d'épreuves standardisées pour l'âge.

Can. J. Neurol. Sci. 2000; 27: 18-24

Although there are many studies on the epidemiology of dementia, there are relatively few longitudinal studies that address progression to dementia in individuals whose cognition was well characterized at baseline. Identifying those at higher risk for the development of dementia is an important goal. Studies indicate that up to $12 \%$ of normal older adults became cognitively impaired over two years ${ }^{1}$ and that up to $80 \%$ of individuals initially identified as cognitively impaired eventually progress to dementia. ${ }^{2-5}$ While a number of variables have been associated with the development of dementia, ${ }^{6-9}$ these factors are often derived from studies of pre-selected groups such as those referred to memory clinics, ${ }^{8}$ and may not be relevant to the general population. They also may not be readily available, requiring genetic testing, neuroimaging, and/or neuropsychological testing.

From the Departments of Medicine and Clinical Neurosciences, University of Calgary, Calgary, AB, Canada

RECEIVED SEPTEMBER 8, 1999. ACCEPTEDINFINALFORMNOVEMBER 30, 1999 Reprint requests to: DBHogan, Health Sciences Centre, University of Calgary, 3330 Hospital Dr., NW, Calgary Alberta T2N 4N1 
The second wave of the Canadian Study of Health and Aging (CSHA) presented a unique opportunity to obtain follow-up data on the cognitive status of a population-based cohort where cognition was well characterized both at baseline (CSHA1) and at the time of follow-up (CSHA2). The objectives of this study were to study incident dementia in the population of survivors who were cognitively normal or cognitively impaired but not demented at baseline. We particularly wanted to identify factors associated with the subsequent development of dementia. Although many variables were collected as part of this study, we were interested in whether those easily attainable could successfully predict cognitive outcome in this population.

Since this population of undemented subjects was previously used by us to examine the utility of various criteria proposed to define mild cognitive impairment ${ }^{10-12}$ we will also report followup data for these various categories of minor degrees of cognitive impairment.

\section{METHODS}

The CSHA1 (1990-1991) was a national, population-based study designed to examine the prevalence of dementia and other aspects of aging in a representative sample of Canadians 65 years of age and older. ${ }^{13}$ For community participants, the study had a two-phase design. An approximately 45 minute long face-to-face screening interview was administered by trained staff. This gathered information on demographics, activities of daily living (ADL), ${ }^{14,15}$ health status (including self-rated health) ${ }^{16}$ and cognition.

Global cognition was assessed by the Modified Mini-Mental State (3MS) examination ${ }^{17}$ where scores can range from 0-100. Higher scores indicate better performance. The $3 \mathrm{MS}$ is a modification of the Mini-Mental State Examination (MMSE). ${ }^{18}$ Four items were added, the scoring system was refined and clearer instructions for scoring were given. ${ }^{17}$ Compared to the MMSE the 3MS has a better sensitivity and specificity for detecting dementia. ${ }^{19}$ The $3 \mathrm{MS}$ can be administered within 20 minutes and requires no special equipment. A MMSE score can be derived from the version of the 3MS used in the CSHA. Individuals who scored less than 78 on the $3 \mathrm{MS}$ and a randomly selected subset of those scoring 78 or more were invited to a clinical examination.

The clinical examination, described in detail elsewhere, ${ }^{13}$ was primarily designed to determine whether dementia was present and to make a specific diagnosis as to the cause, if present. The evaluation consisted of a standardized history, structured informant (a third party identified by the subject as someone who knew them well enough to provide the requested data) interview, screening physical examination, repeat 3MS examination, neurological examination, neuropsychological testing (if the $3 \mathrm{MS}$ score was $>50$ ) and select pre-determined laboratory tests. The neuropsychological test battery was administered by a trained psychometrician and interpreted by a neuropsychologist. The battery included tests of memory, abstract thinking, judgement, constructional abilities, language, familiar object recognition and attention/psychomotor speed (see reference 13 for details). Whenever available, neuropsychological testing was scored using age, gender, and educational level adjusted norms.

Subjects were assigned to diagnostic categories at a consensus conference that integrated all available data.
Participants included the physician(s), study nurse, psychometrician, and neuropsychologist who had evaluated the subject. Patients were categorized as no cognitive loss (NCL), cognitive impairment no dementia (CIND) or demented at this conference. DSM-III-R criteria ${ }^{20}$ was used for the diagnosis of dementia. NINCDS-ADRDA criteria ${ }^{21}$ were used in making a diagnosis of possible or probable Alzheimer's disease (AD). Cognitive diagnostic categories at baseline for the 2,914 subjects who participated in the clinical examination were $\operatorname{NCL}(n=921)$, CIND ( $n=861)$, and dementia $(n=1132 ; n=749$ with a diagnosis of AD). CIND subjects were found to be between cognitively normal subjects and those with dementia in terms of age, 3MS score, general intellectual functioning and performance of activities of daily living. ${ }^{22}$ In the second phase of the study (called CSHA2; 1996-1997) the study cohort was recontacted. The same research methodology with only minor modifications was used. In particular, the clinical assessment, consensus conference, categorization of subjects, and the criteria for dementia remained the same. We were unable to include specific clinical diagnostic data from Newfoundland subjects because a legal interpretation of the province's advance directives legislation found it unacceptable for a proxy to give consent to participate in a research study on behalf of a person unable to give fully informed consent themselves.

We examined follow-up data to determine the cognitive outcome and survival of specific categories of mild cognitive impairment $(\mathrm{MCI})^{10-12}$ whose inclusion criteria captured at least 50 subjects at the time of cohort inception. ${ }^{22}$ The inclusion criteria for these categories are summarized in the footnote to Table 2. We did not utilize the exclusion criteria for these categories in this report as their use would have led to the loss of too many subjects. Further information on how the various groupings were formed is described elsewhere. ${ }^{22}$

\section{Analysis}

Descriptive statistics (mean $\pm \mathrm{SD}$ ), analysis of variance, $\chi^{2}$ (Minitab Statistical Software,Minitab,Inc., Pennsylvania) and logistic regression (BMDP statistical software, California) were performed as indicated in the text.

Bivariate analyses were done first followed by logistic regressions. All variables examined in the bivariate analyses were included in the logistic regression models. Age, education, 3MS score, gender, family history of dementia, informant's report of the subject's memory problems, and OARS ${ }^{15,23}$ derived overall ADL status were considered as potential explanatory variables for the development of dementia or AD. Individuals with missing values for one or more variables were excluded from the logistic analyses. Memory problems were defined as being present when an informant reported difficulties in response to one or both of the following questions: "Does he/she have more difficulty remembering short lists of items, e.g., shopping?" and/or "Does he/she have difficulty remembering recent events, e.g., when he/she last saw you, or what happened the day before?" Family history of dementia was recorded by asking the informant if "any of ... (the subjects') ... relatives have trouble with memory or became very confused and had to go into a home to be looked after?" Age, education and 3MS score were used as continuous variables. Other potential explanatory variables were presented as categorical variables. Potential explanatory variables from the logistic regression 
model were reported if their $p$ value was less than 0.10 . Goodness of fit $\chi^{2}$ (GOF) of the logistic models is described by providing Hosmer-Lemeshow (HL) p values. Sensitivity and specificity of the logisitic regression models are provided. Sensitivity represents the number of cases with predicted probabilities $\geq 0.50$. Specificity is the number of non-demented cases with predicted probabilities $<0.50$.

The results of the logistic regression equation were used to generate a receiver operator curve (ROC). The area under the receiver operating curve is the probability of the model identifying the subjects with a specific outcome when randomly selected pairs of subjects with the outcome and those without the outcome are compared. ${ }^{24}$

Finally, we derived empirically a simplified equation for predicting dementia using the explanatory variables from the logistic regression analyses. Sensitivity and specificity for this simplified model were calculated using standard techniques. As the MMSE is both shorter and more commonly used by physicians, we compared the performance of the simplified equation using either $3 \mathrm{MS}$ results or MMSE scores.

\section{RESULTS}

Among the 1,782 initially non-demented study subjects, forty percent had died by the time of follow-up. Mortality was higher in CIND than in NCL subjects $(48.4 \%$ vs $30.5 \%, \mathrm{p}<.0001)$. Overall, approximately one quarter $(26.9 \%)$ of the non-demented survivors evaluated at time 2 had become demented. One hundred and fifty-nine $(18.9 \%$ of the total population of

Table 1: Comparison of survivors

\begin{tabular}{lllr}
\hline NCL@ CSHA1 & $\begin{array}{l}\text { Not Demented } \\
\text { @ CSHA2 }\end{array}$ & $\begin{array}{l}\text { Demented } \\
\text { @ CSHA2 }\end{array}$ & p \\
& $\mathbf{( 4 5 9 )}$ & $\mathbf{( 7 9 )}$ & \\
Age & $76.9 \pm 6.5$ & $82.1 \pm 5.8$ & $<.001$ \\
\% Female & 62.5 & 69.6 & .23 \\
3MS score & $83.1 \pm 10.3$ & $76.8 \pm 9.5$ & $<.001$ \\
Education (Years) & $9.7 \pm 4.1$ & $8.6 \pm 3.6$ & .02 \\
Family history of dementia & $16.4 \%$ & $16.0 \%$ & .93 \\
Informant reports memory & & & \\
$\quad$ problems & $25.3 \%$ & $40.0 \%$ & .008 \\
ADLstatus ${ }^{1}$ & $2.5 \pm .73$ & $2.8 \pm .95$ & .005 \\
& & & \\
\hline CIND @ CSHA1 & $\mathbf{N o t}$ Demented & Demented & $\mathbf{p}$ \\
& $@$ CSHA2 & @CSHA2 & \\
& $(\mathbf{1 9 3})$ & $\mathbf{( 1 6 1 )}$ & \\
Age & $77.1 \pm 7.0$ & $80.5 \pm 6.9$ & $<.001$ \\
\% Female & 60.1 & 70.8 & .04 \\
3MS score & $73.4 \pm 14.3$ & $66.5 \pm 13.7$ & $<.001$ \\
Education (Years) & $8.1 \pm 3.7$ & $7.9 \pm 3.7$ & .57 \\
family history of dementia & $19.3 \%$ & $25.0 \%$ & .23 \\
Informant reports memory & & & \\
$\quad$ problems & $49.2 \%$ & $67.1 \%$ & .001 \\
ADL status & $2.8 \pm 1.1$ & $3.2 \pm .99$ & .004 \\
& & & \\
\hline
\end{tabular}

${ }^{1}$ OARS derived ADL scores ranged from 2 (excellent/good function) to 6 (total impairment) survivors excluding Newfoundland subjects) were felt to have probable or possible $\mathrm{AD}$. Development of dementia was significantly more common in subjects initially categorized as CIND than in NCL $(42.1 \%$ vs $14.7 \%$, p <.0001) subjects. The characteristics of those who became demented and those who did not are shown in Table 1. A positive family history was the only factor not associated with the development of dementia.

All variables in the bivariate analyses (see Table 1) were considered as potential explanatory variables in our logistic regression analyses for dementia and AD. In NCLsubjects, older age $\left(b_{0}=-5.8, \quad\right.$ coef $/ \mathrm{se}=-2.54 ; b_{1}=.099, \quad$ coef $/ \mathrm{se}=4.1, \quad \mathrm{OR}=1.1$ $(1.05-1.16), \mathrm{p}<.0001)$ and decreased 3MS score $\left(b_{2}=-.048\right.$; coef/se=-3.51, OR=.95 (.93-.98), $\mathrm{p}=.0004)$ were significant explanatory variables for progression to dementia $(\mathrm{HLp}=.79)$. In CIND subjects, decreased 3MS score $\left(b_{0}=-5.86\right.$, coef $/ \mathrm{se}=-2.54$, $\mathrm{b}_{1}=-.064$, coef/se=-3.6, OR=.94 (.90-.97), $\left.\mathrm{p}=.0004\right)$, older age $\left(\mathrm{b}_{2}=.073\right.$, coef/se=2.95, OR=1.08 (1.02-1.13), $\left.\mathrm{p}=.004\right)$ and an informant's report of memory problems $\left(b_{3}=.59\right.$, coef $/ \mathrm{se}=1.72$, OR 1.81 (.92-3.6), $\mathrm{p}=.09$ ) were significant explanatory variables in the model to predict progression to dementia (HL p=.96). When the two groups were combined, decreased 3MS score $\left(b_{0}=-2.69\right.$, coef $/ \mathrm{se}=-1.69 ; b_{1}=-.069$, coef $/ \mathrm{se}=-6.7, \mathrm{OR}=.93(.92-$ $.95), \mathrm{p}<.0001)$, older age $\left(\mathrm{b}_{2}=.081, \mathrm{coef} / \mathrm{se}=4.83, \mathrm{OR}=1.08\right.$ $(1.05-1.12), \mathrm{p}<.0001)$ and an informant's report of memory problems $\left(b_{3}=.72\right.$, coef/se=3.3, OR $\left.2.1(1.3-3.2), p=.0007\right)$ were significant explanatory variables in the model to predict progression to dementia (HL $\mathrm{p}=.45)$. The sensitivity of this logistic regression model for dementia was $27 \%$ and the specificity was $94 \%$.

In NCL subjects, older age $\left(b_{0}=-8.1\right.$, coef $/ \mathrm{se}=-2.88 ; b_{1}=.119$, coef/se $=4.1, \mathrm{OR}=1.13(1.06-1.19), \mathrm{p}<.0001)$ and decreased $3 \mathrm{MS}$ score $\left(b_{2}=-.046\right.$; coef/se $\left.=-2.85, \mathrm{OR}=.96(.92-.99), \mathrm{p}=.004\right)$ were significant explanatory variables for progression to AD (HL $\mathrm{p}=.58)$. In CIND subjects, decreased 3MS score $\left(\mathrm{b}_{0}=-5.86\right.$, coef $/ \mathrm{se}=-2.54, \quad \mathrm{~b}_{1}=-.064, \quad$ coef $/ \mathrm{se}=-3.6, \quad \mathrm{OR}=.94 \quad(.90-.97)$, $\mathrm{p}=.0004)$, older age $\left(\mathrm{b}_{2}=.073\right.$, coef $/ \mathrm{se}=2.95$, OR=1.08 (1.021.13), $\mathrm{p}=.004)$ and an informant's report of a family history of dementia $\left(b_{3}=.59\right.$, coef/se=1.72, OR $\left.1.81(.92-3.6), p=.09\right)$ were significant explanatory variables in the model to predict progression to $\mathrm{AD}(\mathrm{HL} \mathrm{p}=.45)$. When the two groups were combined, decreased $3 \mathrm{MS}$ score $\left(\mathrm{b}_{0}=-3.5\right.$, coef $/ \mathrm{se}=-1.9, \mathrm{~b}_{1}=-.072$, coef/se $=-6.2, \mathrm{OR}=.93(.91-.95), \mathrm{p}<.0001)$, older age $\left(\mathrm{b}_{2}=.087\right.$, coef/se=4.5,OR=1.09 (1.05-1.13), $\mathrm{p}<.0001)$, an informant's report of memory problems $\left(b_{3}=.72\right.$, coef/se=2.9, OR 2.1 (1.3$3.4), \mathrm{p}=.004)$, and an informant's report of a family history of dementia $\left(b_{4}=.54\right.$, coef/se=1.8, OR $\left.1.7(.94-3.1), p=.07\right)$ were significant explanatory variables in the model to predict progression to $\mathrm{AD}$ (HL $\mathrm{p}=.86)$. The sensitivity of this logistic regression model for $\mathrm{AD}$ was $45 \%$ and the specificity was $89 \%$.

\section{ROC}

The ROC for the logistic regression model for predicting dementia in NCL subjects was 0.73 ; the ROC for the model predicting dementia in CIND subjects was also 0.73. The ROC for the combined group was 0.78 .

The ROC for predicting AD was 0.74 for NCL, .75 for CIND and .81 for the combined group.

\section{Simplified model}

Using the results of the logistic regression as a guide, with a 
Table 2: Outcome of Different Types of Mild Cognitive Impairment ${ }^{10-12}$

\begin{tabular}{|c|c|c|c|}
\hline & $\%$ Survivors with Dementia & $\%$ Survivors with $\mathrm{AD}$ & $\%$ Dead \\
\hline Mild Cognitive Impairment (ICD-10 - Type 3)a $(\mathrm{n}=112)$ & 50.9 & 28.8 & 42.4 \\
\hline Mild Cognitive Impairment (DSM-III-R -Type 2) ${ }^{\mathrm{b}}$ (135) & 50.0 & 38.2 & 53.8 \\
\hline Late Life Forgetfulness ${ }^{c}(56)$ & 48.3 & 35.7 & 34.5 \\
\hline Age Associated Cognitive Decline ${ }^{\mathrm{d}}(259)$ & 45.4 & 35.8 & 46.7 \\
\hline Mild Cognitive Impairment (ICD-10 -Type 2) (210) & 34.1 & 21.8 & 52.4 \\
\hline Age Associated Memory Impairment ${ }^{\mathrm{f}}(104)$ & 21.4 & 14.0 & 35.3 \\
\hline Age Consistent Memory Impairment ${ }^{\mathrm{g}}$ (75) & 20.0 & 11.6 & 30.1 \\
\hline
\end{tabular}

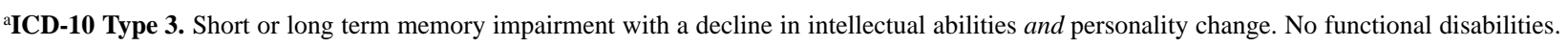

${ }^{\mathrm{b}}$ DSM-III-R Type 2. Short and long term memory impairment and personality change or impairment in at least one of the following: abstract thinking, judgement, higher cortical function (eg, aphasia, apraxia, agnosia). No functional disabilities.

${ }^{c}$ Late-Life Forgetfulness. Subjective memory complaints with gradual onset. Verbal and performance IQ scores between 90 and 130 . Performance between 1 and 2 SDs below the mean established for age on $50 \%$ or more of the test administered.

${ }^{\mathrm{d}}$ Age Associated Cognitive Decline. Gradual decline in any one cognitive area of at least six months duration and performance at least $1 \mathrm{SD}$ below norms for age on relevant neuropsychological tests. These criteria were developed by a working group of the International Psychogeriatrics Association (Wilmette, Illinois) and the World Health Organization (Geneva, Swizerland).

eICD-10 Type 2. Short or long term memory impairment with a decline in intellectual abilities. No functional disabilities.

${ }^{\mathrm{f}}$ Age-Associated Memory Impairment (AAMI). Subjective memory complaints with gradual onset. Verbal and performance IQ scores between 90 and 130. Performance at least 1 SD below the mean established for young adults on one or more tests.

${ }^{g}$ Age-Consistent Memory Impairment (ACMI). Subjective memory complaints with gradual onset. Verbal and performance IQ scores between 90 and 130. Performance within $\pm 1 \mathrm{SD}$ of the mean established for age on $75 \%$ or more of the tests administered.

trial and error approach, we constructed a simplified equation for predicting progression to dementia. The derived equation was: $(100-3 \mathrm{MS}$ score $)+(.25 *$ age $)+10$ (if memory problems were reported by an informant). The results of this equation led to an ROC of 0.72 for NCL, 0.71 for CIND and 0.77 for the entire group (NCLand CIND) in predicting progression to dementia. In the combined group, using a score of 44 or greater to indicate a positive result, yielded a sensitivity of $79.2 \%$ with a specificity of $56.1 \%$.

The equation incorporating the MMSE was: (100-(MMSE/30 $* 100))+(.25 *$ age $)+10$ (if memory problems were reported by an informant). The results of the equation using the MMSE led to an ROC of .73 for NCL, 0.67 for CIND, and .77 for the entire group (NCL and CIND) in predicting the progression to dementia. In the combined group, using a score of 44 or greater as a cutoff, yielded a sensitivity of $72.9 \%$ with a specificity of $67.7 \%$.

\section{Outcome of the various categories of Mild Cognitive Impairment}

The rates of developing dementia among the survivors of different categories of MCI were significantly different $(\mathrm{p}=.0007)$, ranging from 20 to 51 per cent (see Table 2). MCI (ICD-10-Type 3), MCI (DSM-IIIR-Type2), LLF and AACD showed the highest conversion rates. The subsequent rates of dementia found for these four categories were not significantly different $(\mathrm{p}=.88)$. The rate for developing $\mathrm{AD}$ ranged from 11 to 38 per cent $(\mathrm{p}=.003)$ but there were no significant differences between the four categories with the highest rates $(p=0.76)$. Mortality rates were also significantly different between groupings $(\mathrm{p}=.002)$ and ranged from 30.1 to 53.8 per cent.

\section{DISCUSSION}

These results suggest that simple, easily obtained variables may be useful in predicting the likelihood of the development of dementia in seniors over a five year period. Our results, from a large population-based cohort, confirmed earlier work that showed that age, ${ }^{25,26}$ Mini-Mental Status Examination score ${ }^{27}$ and caregiver identification of memory difficulties ${ }^{28,29}$ were important risk factors for the development of dementia. These three easily determined factors led to a predictive equation of reasonable sensitivity.

Other variables that have been associated with a higher risk of progression include subitems from the 3MS/MMSE (such as recall and time orientation) $)^{30}$ and educational attainment. ${ }^{31} \mathrm{We}$ used the total $3 \mathrm{MS}$ score rather than components of the $3 \mathrm{MS}$. While associated with the outcome of interest, the components of the 3MS did not perform as well as the total 3MS score. Educational level was associated with the subsequent development of dementia in NCL subjects, but it was not a significant explanatory variable in the logistic models. There was no evidence in our study that family history was an important predictor for the progression to dementia though it was associated with a higher risk of developing AD.

Low scores on select neuropsychological tests, ${ }^{32}$ specific neuroradiologic features, ${ }^{33}$ comorbidity, ${ }^{34,35}$ and Apo E genotype ${ }^{36}$ have also been associated with subsequent cognitive decline, but they may not be feasible to obtain in routine clinical practice. Studies from other CSHAinvestigators will report on the role of neuropsychology and genetic testing for apolipoprotein $\mathrm{E}$ allele in predicting the development of dementia in this cohort. In this report we deliberately chose to deal only with variables that 
could be easily determined in the course of a single clinical encounter by a non-specialist practitioner without access to laboratory/radiological investigations.

The follow-up data on the different categories of cognitive impairment show that the inclusion criteria for some categories were more successful than others at describing impaired individuals at higher risk for progression to dementia. Some of the groups at higher risk for dementia were characterized by the requirement for neuropsychological test scores that were greater than 1 standard deviation (SD) below the mean of age-based normative data (e.g., AACD, LLF). The CSHA study diagnosis of CIND, while less rigorously determined, had a similarly high rate of progression to dementia. The neuropsychologists who participated in the CSHA generally required scores of at least 1 SD below the norms for a neuropsychological test (taking into account educational background, sensory impairments, test characteristics, and the pattern of results) before they would declare that an impairment was present. We used their opinion to determine the presence of impairments for ICD-10-types 2 and 3 and DSM-III-R type 2. Groups at lower risk were those who were judged impaired when compared to young adults (AAMI) or whose scores fell within $1 \mathrm{SD}$ of the mean for age based norms (ACMI). The rate of progression to dementia in these groups was similar to CSHA1 subjects categorized as NCL. These results suggest that appropriate criteria for significant cognitive impairment (defined as a high likelihood of progression to dementia) using neuropsychological test performance should define impairment as a score of at least $1 \mathrm{SD}$ below an age-based mean.

Limitations were present in our study. We report on a population that was predominately Caucasian $(98.5 \%)$. The long lapse before the follow-up examination (mean five years) and the high mortality rate resulted in the loss of valuable information. Forty percent of the subjects had died during these five years. Principally because of the way subjects were selected for the clinical examination, the annual mortality rate of approximately 80 per 1000 was higher than one would expect to find for a similarly aged unselected Canadian population. The reported age-specific death rate for Canadians aged 75-79 in 1991 was 46.7 per 1000 and 45.5 per 1000 in $1992 .{ }^{37}$ In addition, those who refused to undergo the clinical assessment may have done so because of a reluctance to have an already suspect cognitive state assessed. ${ }^{38}$ These limitations might weaken the generalizability of our results. The specificity of our predictive instrument (using 43/44 as the cut point) was poor. The predictive equation using the MMSE worked as well as the one utilizing the 3MS score. Our study suggests that for determining the risk of a future dementia the $3 \mathrm{MS}$ offers no clear advantage over the MMSE.

In a pre-selected population (non-demented patients referred by their family physician with a $3+$ month history of symptomatic memory problems that interfered with daily functioning) and using a battery that included neuropsychological test results, Tierney et al reported a sensitivity of $75.9 \%$ and a specificity of $93.6 \%$ in the prediction of probable AD. ${ }^{8}$ Our specificity (89\%) for predicting probable and possible $\mathrm{AD}$ derived in a representative sample of Canadians 65 years and older may be more applicable to the general population.

In our population-based study we found that simple measures were able to select those at higher risk for developing dementia. Our simplified approach may be useful in identifying a higher risk group for more intensive monitoring and/or the administration of safe, inexpensive interventions (e.g., secondary prevention by risk factor modification or by the use of antioxidants, non-steroidal anti-inflammatory agents or estrogen replacement therapy in women). Further studies are needed to prove the utility of these potential interventions. The different categories of cognitive impairment as described in the literature have significantly different outcomes. The accuracy of predicting outcomes will likely be improved by incorporating laboratory, radiological, and neuropsychological data but at the cost of ease of use.

\section{ACKNOWLEDGEMENTS}

The data reported in this article were collected as part of the Canadian Study of Health and Aging. The core study was funded by the Seniors'Independence Research Program, through the National Health Research and Development Program (NHRDP) of Health Canada (project no. 6606-3954-MC (S)). Additional funding was provided by Pfizer Canada Incorporated through the Medical Research Council/ Pharmaceutical Manufacturers Association of Canada Health Activity Program, NHRDP(project no. 6603-1417-302 (R)), Bayer Incorporated, and the British Columbia Health Research Foundation (projects no. 38 (93-2) and no. 34 (96-1)). The study was coordinated through the University of Ottawa and the Division of Aging and Seniors, Health Canada.

\section{REFERENCES}

1. Flicker C, Ferris SH, Reisberg B. A two-year longitudinal study of cognitive function in normal aging and Alzheimer's disease. J Geriatr Psychiatry Neurol 1993;6:84-96.

2. Devanand DP, Folz M, Gorlyn M, Moeller JR, Stern Y. Questionable dementia: clinical course and predictors of outcome. J Am Geriatr Soc 1997;45(3):321-328.

3. Petersen RC, Smith GE, Tangalos EG, Kokmen E, Ivnik RJ. Longitudinal outcome of patients with a mild cognitive impairment. Ann Neurol 1993;34:294-295.

4. O'Neill D, Surmon DJ, Wilcock GK. Longitudinal diagnosis of memory disorders. Age and Ageing 1992;21:393-397.

5. Koven MG. Health of the elderly and use of health services. Pub Health Reports 1977;92:9-15.

6. Tierney MC, Szalai JP, Snow WG, et al. A prospective study of the clinical utility of ApoE genotype in the prediction of outcome in patients with memory impairment. Neurology 1996;46:149-154.

7. Jack CR, Petersen RC, Xu YC, et al. Prediction of AD with MRIbased hippocampal volume in mild cognitive impairment. Neurology 1999;52:1397-1403.

8. Tierney MC, Szalai JP, Snow WG, et al. Prediction of probable Alzheimer's disease in memory-impaired patients: a prospective longitudinal study. Neurology 1996;46:661-665.

9. Petersen RC, Smith GS, Ivnik RJ, et al. Apolipoprotein E status as a predictor of the development of Alzheimer's disease in memory-impaired individuals. JAMA1995;273:1274-1278.

10. Zaudig M. Anew systematic method of measurement and diagnosis of "Mild Cognitive Impairment" and dementia according to ICD-10 and DSM-III-R Criteria. Int Psychogeriatr 1992;4 Suppl 2:203-219.

11. Crook T, Bartus RT, Ferris SH, et al. Age-associated memory impairment: proposed diagnostic criteria and measures of clinical change - report of a National Institute of Mental Health Work Group. Dev Neuropsychol 1986;2:261-276.

12. Blackford RC, La Rue A. Criteria for diagnosing age-associated memory impairment: proposed improvement from the field. Dev Neuropsychol 1989;5:295-306.

13. Canadian Study of Health and Aging. Canadian study of health and aging-study methods and prevalence of dementia. Can Med Assoc J 1994;150:899-913. 
14. McDowell I, Newell C. Measuring Health: a Guide to Rating Scales and Questionnaires. New York: Oxford University Press, 1987: 47.

15. Fillenbaum GG. Multidimensional functional assessment of older adults: the Duke Older Americans Resources and Services Procedure. New Jersey: Lawrence Erlbaum Associate, 1988: 125.

16. Ebly EM, Hogan DH, Fung TS. Correlates of self-rated in persons aged 85 and over: results from the Canadian Study of Health and Aging. Can J Public Health 1996;87:28-31.

17. Teng EL, Chui HC. The Modified Mini-Mental State (3MS) examination. J Clin Psychiatr 1987;48:314-318.

18. Folstein MF, Folstein SE, McHugh PR. Mini-Mental State - a practical method for grading the cognitive state of patients for the clinician. J Psychiatric Res 1975;12:189-198.

19. McDowell I, Kristjansson B, Hill GB, Hebert R. Community screening for dementia - the Mini Mental State Exam (MMSE) and Modified Mini Mental State (3MS) compared. J Clin Epidemiol 1997;(50):377-383.

20. American Psychiatric Association. Diagnostic and Statistical Manual of Mental Disorder (3rd Ed. rev.) Washington DC. Washington DC 1987.

21. McKhann G, Drachman D, Folstein M, et al. Clinical diagnosis of Alzheimer's disease: report of the NINCDS-ADRDA work group. Neurology 1984;34:939-944.

22. Ebly EM, Hogan DH, Parhad IM. Cognitive impairment in the nondemented elderly: results from the Canadian Study of Health and Aging. Arch Neurol 1995;52:612-619.

23. Schaie KW, Parham IA. Cohort-sequential analyses of adult intellectual development. Dev Psychol 1977;13:649-653.

24. Murphy JM, Berwick DM, Weinstein MC, et al. Performance of screening and diagnostic tests: application of receiver operating characteristic analysis. Arch Gen Psychiatry 1987;44:550-555.

25. Gao S, Hendrie HC, Hall KS, Hui S. The relationship between age, sex, and the incidence of dementia and Alzheimer's disease. Arch Gen Psychiatry 1998;55(9):809-815.

26. Jorm AF, Jolley D. The incidence of dementia: a meta-analysis. Neurology 1998;51(3):728-733.
27. Dartigues JF, Commenges D, Letenneur D, et al. Cognitive predictors of dementia in elderly community residents. Neuroepidemiology 1997;16(1):29-39.

28. McGlone J, Gupta S, Humphrey D, et al. Screening for early dementia using memory complaints from patients and relatives. Arch Neurol 1990;47:1189-1193.

29. Tierney MC, Szalai JP, Snow WG, Fisher RH. The prediction of Alzheimer's disease. The role of patient and informant perceptions of cognitive deficits. Arch Neurol 1996;53(5):423427.

30. Small BJ, Vitanen M, Backman L. Mini-Mental State Examination item scores as predictors of Alzheimer's disease: incidence data from the Kungsholmen Project, Stockholm. J Gerontol 1997; 52(5): M299-304.

31. Albert MS, Jones K, Savage CR, et al. Predictors of cognitive change in older persons: MacArthur studies of successful aging. Pyschol Aging 1995;10(4):578-589.

32. Rubin EH, Storandt M, Miller JP, et al. A prospective study of cognitive function and onset of dementia in cognitively healthy elders. Arch Neurol 1998;55(3):395-401.

33. Kaye JA, Swihart T, Howieson D, et al. Volume loss of the hippocampus and temporal lobe in healthy elderly persons destined to develop dementia. Neurology 1997;48(5):1297-1304.

34. Stewart R, Liolitsa D. Type 2 diabetes mellitus, cognitive impairment and dementia. Diabet Med 1999;16(2):93-112.

35. Yaffe K, Blackwell T, Gore R, et al. Depressive symptoms and cognitive decline in nondemented elderly women: a prospective study. Arch Gen Psychiatry 1999;56(5):425-430.

36. Tilvis RS, Strandberg TE, Juva K. Apolipoprotein E phenotypes, dementia and mortality in a prospective population sample. J Am Geriatr Soc 1998;46(6):712-715.

37. Statistics Canada. Health Statistics Division: Deaths 1992. Ottawa: Statistics Canada, 1995, 17.

38. Norton MC, Breitner JC, Welsh KA, Wyse BW. Characteristics of nonresponders in a community survey of the elderly. $\mathrm{J}$ Am Geriatr Soc 1994;42(12):1252-1256. 


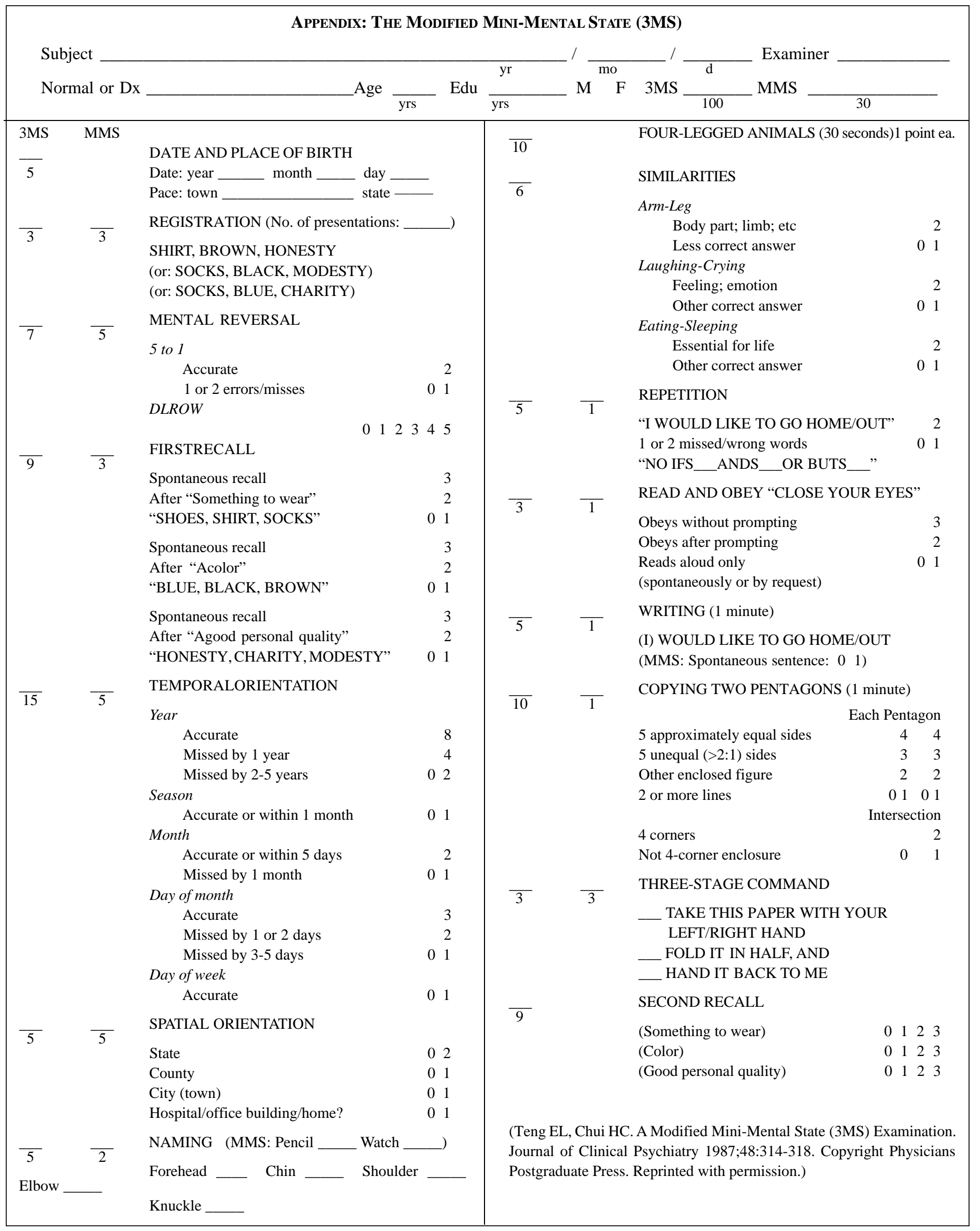

